\title{
Progress of Research on the Mechanisms by Which Yoga Contributes to the Rehabilitation of Chronic Low Back Pain
}

\author{
Cui Cui Wang and Xinyan Zheng* \\ Department of Exercise and Health Sciences, China
}

*Corresponding author: Xinyan Zheng, Key Laboratory of Exercise and Health Sciences of the Ministry of Education, China.

Received Date: October 20, 2019

Published Date: December 09, 2019

\section{Introduction}

Back pain is the most common human spinal disorder. It can be caused by lesions in the skin, subcutaneous tissue, muscles, ligaments, spine, ribs, spinal cord, and meninges. Low back pain typically manifests in the lower lumbar spine and lumbosacral and sacroiliac regions. It is usually dull and tingling, with local tenderness and/or radiation along the lower extremities. It is often accompanied by inadequate movement capability, pitching inconvenience, lack of weight-bearing ability, walking difficulty, and/or limb fatigue. More severe symptoms are forward lumbar bending, back extension, scoliosis, and spinal deformity. The 3 -month prevalence rate of low back pain is estimated to be $25 \%$, and the lifetime prevalence rate is estimated to be as high as $84 \%$ [1-3]. Low back pain poses a great societal and economic burden, as it is related to a decline in work efficiency, poor quality of life, and high medical costs [4]. Its treatment forms the largest category of medical claims (20-25\%) [5], with direct medical costs exceeding $\$ 34$ billion annually [6].

Chronic low back pain (CLBP), Defined as low back pain persistence for $>3$ months [7], can be caused by

- Traumatic, degenerative (spinal stenosis), and inflammatory conditions.

- Paravertebral soft-tissue diseases and lumbar muscle degeneration.

- Stimulation of the spinal cord and spinal nerve root, spinal cord compression, or acute myelitis.

- $\quad$ Visceral diseases (e.g., pleurisy, pyelonephritis).

- Mental factors or chronic fatigue syndrome.
- Occupational factors (e.g., excessive bending/twisting, restrictive work position, vibration, heavy physical labor, monotonous repetitive work) and insufficient leisure activities.

Patients with CLBP can develop functional disability [8], sleep disorders, fatigue, and drug abuse [9]. CLBP is the most common cause of large workday losses and disability claims [10]. About $1 \%$ of the American population (men and women) has chronic disability due to low back pain [11].

The pathogenesis of CLBP involves mechanical instability and inflammatory factors that stimulate nerve endings. Spinal instability means that under a normal physiological load, the spine cannot maintain the normal interbody anatomical relationship without secondary injury to the spinal cord or nerve root, and without pain or dysfunction caused by structural changes (deformities). Many studies have confirmed the relationship between proprioceptive disorder and CLBP.

The rehabilitation of chronic pain, considered as a chronic disease, should rely greatly on patients' self-management, with family and social support [12]. Most patients depend on their doctors and lack relevant guidance after leaving the hospital, especially with regard to back rehabilitation exercises. Current treatments for CLBP include bed rest, medication, traction, local closure, physiotherapy, and exercise therapy [13]. Poor self-management behavior is the main factor affecting CLBP rehabilitation outcomes, leading to recurrence. Exercise and the maintenance of a certain lower-back activity range are considered to effectively reduce pain intensity and to improve the functional status of patients with CLBP, and exercise is commonly advocated as a first-choice treatment [14-16]. Indeed, a recent clinical practice guideline from 
the American College of Physicians strongly recommends exercise therapy interventions for CLBP [17]. The best form and duration of such exercise, however, remain open questions.

Yoga originated in India thousands of years ago and has become popular throughout the world; about 14.9 million people in the United States practice yoga [18]. Yoga provides a self-correcting, holistic approach to health and has been shown to be effective for several chronic lifestyle-related diseases, such as osteoarthritis [19], rheumatoid arthritis [20], essential hypertension [21], bronchial asthma [22,23], irritable bowel syndrome [24], diabetes [25], arterial disease [26], and depression [27]. It is an increasingly common and effective treatment for pain and related disabilities $[28,29]$, including chronic muscle pain-related diseases [30] such as CLBP. In recent years, the use of complementary alternative medicines (CAMs) has increased by nearly $10 \%$; back pain is the most common cause of use [31], and yoga is among the most common CAM activities [32,33]. In the 2002 National Health Interview Survey on supplemental and alternative medicines, more than 10 million American adults reported the use of yoga for health reasons; $10.5 \%$ of yoga practitioners reported that they used yoga for musculoskeletal diseases, and $76 \%$ reported that yoga was helpful [34]. Thus, an understanding of the effect of yoga on CLBP rehabilitation could use the design of yoga-based interventions to reduce or treat CLBP.

\section{Characteristics and Effects of Yoga}

Yoga is composed mainly of breathing, postures, and meditation, leading to smoothing of the whole-body meridian Qi, improvement of blood circulation, gland stimulation to balance secretion, function-activating visceral massage, nerve relaxation, muscle extension, flexibility development, enhanced immune system function [35],increased antioxidant defense enzymes and promotion of the delay of cell aging [36]. Yoga can improve the electrical activity of brain cells, which is conducive to brain control, and adjust the functions of various viscera, especially those of the endocrine system [37]. Yoga practice can thus benefit a wide range of people. The difficulty and amount of yoga exercise are easy to control, and yoga has low facilities and equipment requirements. Consistent yoga practice can improve fitness, temperament, and mood [22]. With the acceleration of the speed and complexity of life, yoga is regarded as a part of the new "green" lifestyle, adopted by increasing numbers of people as a light inner- and outer-body fitness technique.

Controlled yogic breathing balances the autonomic (sympathetic) nervous system and reduces habitual muscle and skeletal tension, thereby reducing fatigue and stress [38,39]. Yogic breathing differs from usual superficial breathing in that it is deep, slow, uniform, and rhythmic, involving the larynx, thorax, and abdomen, and thus diaphragmatic movement. The alveolar ventilation volume reaches $5100 \mathrm{ml} / \mathrm{min}$, much higher than that of normal breathing. Breath-adjustment exercises accompanied by appropriate music can help the practitioner to enter a stable and quiet state, improve consciousness and muscle perception, and enhance nerve control ability for the respiratory and muscular systems, thereby preparing him or her for physical and mental exercises. Yoga posture practice is a delicate and slow process involving twisting, squeezing, stretching, and pulling. It starts with simple postures that gradually develop practitioners' physical perception and motor ability. Yogic movement enriches the blood supply and flow to deep tissue, improving microcirculation [37]. Meditation is a key part of yoga practice; it helps the practitioner concentrate, so that the brain can understand the world more clearly and feel subtle changes in the body.

Lemay et al. [40] found that the performance of mindfulness exercises at least once a week alleviated college students' stress and anxiety. Indian medical experts have found that yoga postures have positive effects on blood glucose control and nerve conduction and can reduce the clinical neuropathy of H-deficiency diabetes [41]. In a study conducted in Thailand, yoga reduced blood pressure in hypertensive patients [42]. Yoga also has a positive effect on the treatment of stubborn obstructive diseases, it has been reported that women who often take part in yoga have a $30-40 \%$ reduction in the incidence of breast cancer [43].

\section{Research on yoga for CLBP rehabilitation}

Many studies have demonstrated that yoga plays an important role in CLBP rehabilitation. In a systematic analysis, Posadzki P et. al [44] showed that yoga reduced CLBP significantly more effectively than did conventional exercise. Michael et al. [45] compared the effects of yoga and Qigong as rehabilitation training for patients with CLBP. The results showed that participating in a 3-month yoga or qigong program did not improve chronic back pain, back function and quality of life during a 3- or 6-month period. Keosaian, et al. [46] explored the experiences of low-income minority adults taking part in a yoga dosing trial for chronic low back pain that has the potential to favorably impact health in a predominantly lowincome minority population. It confirmed that yoga is an effective multidimensional treatment for CLBP. Patricia, et al. [47] showed that yoga significantly reduced pregnancy-related low back pain. Goode, et al. [48] drew an evidence map for the efficacy of yoga for CLBP, evidence suggests benefit of yoga in midlife adults with non-specific CLBP for short- and long-term pain and back-specific disability, but the effects of yoga for health-related quality of life, wellbeing and acute LBP are uncertain. Without additional studies, further systematic reviews are unlikely to be informative. Williams, et al. [49] compared the effects of Iyengar yoga and standard medical care as rehabilitation training for adults with CLBP; after 6 months of treatment, yoga had improved functional disorders, pain intensity, and depression, and reduced analgesic use, compared with the control group. Sherman, et al. [50] found that when compared to a self-care book, 12 weekly 75-minute Viniyoga classes resulted in both statistically and clinically significant improvements in functional status but when compared to conventional therapeutic exercises, were statistically significant but not clinically important. Padmini Tekur and others [51] found that short-term intensive comprehensive yoga training reduced pain and dysfunction, and increased spinal flexibility, in patients with CLBP. 


\section{Mechanism of yoga's contribution to CLBP rehabilitation}

Through progressive stretching and twisting posture exercises, yoga can alleviate lumbar muscle spasm, release adhesion, enhance lumbar spine stability, and increase the joint range of motion [52]. It has been found to increase hip flexion and spinal and hamstring flexibility in patients with low back pain [53,54]. The coordination of breathing and posture exercises enables the inhaled energy to reach the deepest tissues, resulting in musculoskeletal stretching, increased capillary opening, improved blood supply, and promotion of oxygen and metabolite transportation; further strengthening exercise can provide more abundant oxygen to all tissues of the body, increasing the oxygen content of blood and purifying it [52], thereby improving the blood supply and metabolism of the waist soft tissue.

The mechanism by which yoga relieves pain, however, is not completely clear. It may be related to decreased nerve or physiological sensitivity of painful tissue or to a change in the adaptability of compressed tissue. Harte [55] found increased endorphins and enkephalin in yoga practitioners, with the release of these analgesic substances effectively alleviating pain.

From the perspectives of biomechanics and anatomy, yoga can strengthen the lumbar extensor muscles (including the polyfidus and sacrospinal muscles) and abdominal muscles, providing support for the spine; spinal twisting stimulates the intervertebral discs and articular capsules, stretch in the direction of rotation promotes spinal rotation and vertebral mobility, and polyfidus muscle contraction-reduction-relaxation cycles comprise effective training. These effects conform to the principles of strength training and muscle stretch [56]. Yoga exercises effectively maintain overall spinal stability and flexibility, reduce the pressure between vertebral bodies, and correct slight displacements of the lumbar intervertebral discs and foramina. It can also ease nerve root compression, and alleviate or avoid common conditions related to CLBP, such as lumbar disc herniation. In addition, psychological effects of yoga can contribute to CLBP rehabilitation. Yoga can relieve depression, and fear [49]. Studies have shown that meditation can alleviate fear [57], enhance self-belief and improve the pain-coping ability of patients with chronic pain [7].

\section{Matters Needing Attention in Yoga Practice}

Reasonable yoga practice has a certain effect on CLBP rehabilitation, but unsuitable practice can be a source of injury. Attention must be paid to the following points in yoga practice. First, the dorsal (including lumbar) and abdominal muscles should be exercised at the same time to enhance the balancing of their strength, with consideration of the lumbar curvature and the size of sacral tilt.

Second, yoga posture practice should fully consider the practitioner's flexibility, balance, and strength. Stretching should be performed gently and slowly, within the body's limits and without excessive drag, to prevent muscle strain. The practitioner should explore and gradually understand the state of his or her body, pay attention to the anatomical characteristics of the correct positions, and protect the joints; exercise intensity should be increased gradually.

Third, the practitioner should focus on the feeling of the physical exercise, perceiving the effects of each action. Only by actively guiding the practice can physical and mental relaxation be achieved. Fourth, rehabilitation training plans to improve the physical fitness of corresponding muscle groups should be formulated scientifically according to the degree of CLBP, to establish the correct exercise mode. In addition, the practice should include full preparatory activities and post-exercise meditation to take full advantage of the adjustments and recovery of function achieved.

\section{Conclusion}

As a form of fitness, yoga plays an important role in CLBP rehabilitation. It strengthens the lumbar and dorsal extensors, increases spinal stability, reduces pressure on the intervertebral discs, and promotes circulation. Thus, yoga can improve pain and dysfunction in patients with CLBP. In addition, it can reduce fatigue, thereby improving overall health and the number of visits to doctors and hospitals. Therefore, yoga has good cost and social benefits, and is worth promoting in clinical and community settings. However, as with other forms of chronic disease management, the improvement of patients' long-term yoga compliance, and beliefs about and motivation to perform yoga, is the key to the achievement of successful effects.

\section{Acknowledgment}

None.

\section{Conflict of Interest}

No conflict of interest.

\section{References}

1. Deyo RA, Mirza SK, Martin BI (2006) Back pain prevalence and visit rates: estimates from US, national surveys, 2002. Spine (Phila Pa 1976) 31(23): 2724-2727.

2. Balague F, Mannion AF, Pellise F, Cedraschi C (2012) Nonspecific low back pain. Lancet 379(9814): 482-491.

3. Hoy D, Bain C, Williams G, March L, Brooks P, et al. (2012) A systematic review of the global prevalence of low back pain. Arthritis Rheum 64(6): 2028-2037.

4. Dagenais S, Caro J, Haldeman S (2008) A systematic review of low back pain cost of illness studies in the United States and internationally. Spine J 8(1): 8-20.

5. Shelerud R (1998) Epidemiology of occupational low back pain. Occup Med 13(1): 1-22.

6. Frymoyer JW, Durett CL (1997) The economics of spinal disorders. In: Frymoyer JW, (ed) The adult spine: Principles and practice. $\left(2^{\text {nd }}\right.$ edn), Lippincott Raven, USA, pp. 143-150.

7. Schütze R, Rees C, Preece M, et al. (2010) Low mindfulness predicts pain catastrophizing in a fear-avoidance model of chronic pain. Pain 48(1): 120-127.

8. Williamas AC, Nicholas MK, Richardson PH (1993) Evaluation of a cognitive behavioral program for rehabilitating patients with chronic pain. Br J Gen Pract 43(377): 513-518.

9. Moldofsky H, Lue FA (1993) Disordered sleep, pain, fatigue and gastrointestinal symptoms in fibromyalgia, chronic fatigue and irritable bowel syndromes. In: Mayer EA, Raybould HE, (eds) Basic and Clinical Aspects of Chronic Abdominal Pain. Elsevier Science, USA, pp. 249-255. 
10. Franks JW, Kerr MS, Brooker AS, Demano SE (1996) Disability resulting from occupational low back pain: A review of scientific evidence on prevention before disability begins. Spine (Phila Pa 1976) 21(24): 29082917.

11. Andersson GBJ (1997) The epidemiology of spinal disorders. In Frymoyer JW, (ed), The Adult Spine: Principles and Practice, $\left(2^{\text {nd }}\right.$ edn), Lippincot-Raven, USA, pp. 93-141.

12. Andrew B, Lisa W, Cheryl H (2008) Evaluation of a multidisciplinary back pain rehabilitation programm individual and group perspectives. Qual Life Res 17(3): 357-366.

13. Rissanen A, Kalimo H, Alaranta H (1995) Effect of intensive training on the isokinetic strength and structure of lumbar muscles in patients with chronic low back pain. Spine (Phila Pa 1976) 20(3): 333-340.

14. Chou R, Huffman LH (2007) American Pain Society, American College o Physicians. Nonpharmacologic therapies for acute and chronic low back pain: a review of the evidence for an American Pain Society/ American College of Physicians clinical practice guideline. Ann Intern Med 147(7): 492-504.

15. Langevin HM, Sherman KJ (2007) Pathophysiological model for chronic low back pain integrating connective tissue and nervous system mechanisms. Med Hypotheses 68(1): 74-80.

16. Van Middelkoop M, Rubinstein SM, Verhagen AP (2010) Exercise therapy for chronic nonspecific low-back pain. Best Pract Res Clin Rheumatol 24(2): 193-204.

17. Qaseem A, Wilt TJ, Mc Lean RM (2017) Noninvasive treatments for acute, subacute, and chronic low back pain: a clinical practice guideline from the american college of physicians. Ann Intern Med 166(7): 514-530.

18. Saper RB, Eisenberg DM, Davis RB, Culpepper L, Phillips RS (2004) Prevalence and Patterns of Hatha Yoga Use in the United States: Results of a National Survey. Altern Ther Health Med 10(2): 20-21.

19. Garfinkel MM, Singhal A, Katz WA (1998) Yoga based intervention for carpel tunnel syndrome: A randomized trial. JAMA 280(18): 1601-1603.

20. Haslock I, Monro R, Nagarathna R (1994) Measuring the effects of yoga in rheumatoid arthritis. Br J Rheumatol 33(8): 787-790.

21. Murugesan R, Govindarajulu N, Bera TK (2000) Effect of selected yogic practices on the management of hypertension. Indian J Physiol Pharmacol 44(2): 207-210.

22. Nagarathna R, Nagendra HR (1985) Yoga for bronchial asthma: A controlled study. Br Med J (Clin Res Ed) 291(6502): 1077-1079.

23. Vedanthan PK, Keshavulu LN, Murthy KC (1998) Clinical study of yoga techniques in university students with asthma: A controlled study. Allergy Asthma Proc 19(1): 3-9.

24. Taneja I, Deepak KK, Poojary G (2004) Yogic versus conventional treatment in diarrhea-predominant irritable bowel syndrome: A randomized control study. Appl Psychophysiol Biofeedback 29(1): 2919-2933

25. Singh S, Malhotra V, Singh K, Sharma S (2001) A preliminary report on the role of yoga asanas on oxidative stress in non-insulin dependent diabetes. Indian J Clin Biochem16(2): 216-220.

26. Manchanda SC, Narang R, Reddy KS (2000) Retardation of coronary atherosclerosis with yoga lifestyle intervention. J Assoc Physicians India 48(7): 687-694.

27. Woolery A, Myers H, Sternlieb B, Zeltzer L (2004) A yoga intervention for young adults with elevated symptoms of depression. Altern Ther Health Med 10(2): 60-63.

28. Mc Call T (2007) Yoga as Medicine. Bantam Dell, USA.

29. Bussing A, Ostermann T, Ludtke R, Michalsen A (2012) Effects of yoga interventions on pain and pain-associated disability: a meta-analysis. J Pain 13(1): 1-9.

30. Carneiro KA, Rittenberg JD (2010) The role of exercise and alternative treatments for low back pain. Phys Med Rehabil Clin N Am 21(4): 77-92.
31. Eisenberg DM, Davis RB, Ettner SL (1998) Trends in alternative medicine use in the United States, 1990-1997: Results of a follow-up national survey. JAMA 280(18): 1569-1575

32. Barnes PM, Powell Griner E, Mc Fann K, Nahin RL (2004) Complementary and alternative medicine use among adults: United States, 2002. Adv Data 343: 1-19.

33. Wolsko PM, Eisenberg DM, Davis RB, Kessler R, Phillips RS (2003) Patterns and Perceptions of Care for Treatment of Back and Neck Pain: Results of a National Survey. Spine (Phila Pa 1976) 28(3): 292-297.

34. Birdee GS, Legedza AT, Saper RB, Bertisch SM, Eisenberg DM, et al (2008) Characteristics of yoga users: results of a national survey. J Gen Intern Med 23(10): 1653-1658.

35. Das SN, Kochupillai V, Singh D (2002) Flowcytometric study of T-cell subset and natural killer cells in peripheral blood of Art of Living teachers, normal subjects and cancer patients. Proceedings Science of Breath International Symposium on Sudarshan Kriya, Pranayam \& Consciousness. All India Institute of Medical Sciences, India.

36. Sharma H, Aggarwal D, Sen S (2002) Effects of Sudarshan Kriya on antioxidant status and blood lactate level. Proceedings Science of Breath International Symposiumon Sudarshan Kriya, Pranayam\& Consciousness. All India Institute of Medical Sciences, India.

37. Ross A, Thomas S (2010) The health benefits of yoga and exercise: a review of comparison studies. J Altern Complement Med 16(1): 3-12.

38. Brown RP, Gerbarg PL (2005) Sudarshan Kriya Yogic breathing in the treatment of stress, anxiety, and depression: Part II-- clinical applications and guidelines. J Altern Complement Med 11(4): 711-717.

39. Telles S, Nagarathna R, Nagendra HR (1994) Breathing through a particular nostril can alter metabolism and autonomic activities. Indian J Physiol Pharmacol 38(2): 133-137.

40. Lemay Virginia, Hoolahan John, Buchanan Ashley (2019) Impact of a Yoga and Meditation Intervention on Students' Stress and Anxiety Levels. Am J Pharm Educ 83(5): 7001.

41. Me Caffrey, R, Ruknui P, Hatthakit U (2005) The effects of yoga on Hypertensive persons in Thailand. Holist Nurs Pract 19(4): 173-80.

42. Garfinkel MS, Singhal A Katz WA (1999) Yoga based intervention for carpaltunnel syndrome: a randomized trial. JAMA 280(22): 1601-1603.

43. Malhotra V, Singh S, Tandon OP (2002) Effect of Yoga as anason nerve conduction in type2 diabetes. Indian J Physiol Pharmacol 46(3): 298306.

44. Posadzki P, Ernst E (2011) Yoga for low back pain: a systematic review of randomized clinical trials. Clin Rheumatol 30(9): 1257-1262.

45. Michael T, Judith K, Dorothea D (2016) Qigong or yoga versus no intervention in older adults with chronic low back pain--a randomized controlled trial. J Pain 17(7): 796-805.

46. Keosaian JE, Lemaster CM, Dresner D (2016) We're all in this together: a qualitative study of predominantly low-income minority participants in a yoga trial for chronic low back pain. Complement Ther Med 24: 34-39.

47. Kinser PA, Pauli J, Jallo N (2017) Physical activity and yoga-based approaches for pregnancy-related low back and pelvic pain. J Obstet Gynecol Neonatal Nurs 46(3): 334-346.

48. Goode AP, Coeytaux RR, Mcduffie J (2016) An evidence man of yoga for low back pain. Complement Ther Med 25: 170-177.

49. Willams K, Abildso C, Steinberg L (2009) Evaluation of the Effectiveness and Efficacy of Iyengar Yoga Therapy on Chronic Low Back Pain. Spine (Phila Pa 1976) 34(19): 2066-2076.

50. Sherman KJ, Cherkin DC Erro J, Miglioretti DL, Deyo RA (2005) Comparing yoga, exercise, and a selfcare book for chronic low back pain: A randomized, controlled trial. Ann Intern Med 143(12): 849-856.

51. Tekur P, Singphow C, Nagendra HR, Raghuram N (2008) Effect of shortterm intensive yoga program on pain, functional disability and spina flexibility in chronic low back pain: a randomized control study. J Altern Complement Med 14(6): 637-644. 
52. George SZ, Wittmer VT, Fillingim RB (2010) Comparison of graded exercise and gradeed exposure clinical outcomes for patient switch chronic low back pain. J Orthop Sports Phys Ther 40(11): 694-704.

53. Galantino ML, Bzdewka TM, Eissler Russo JL, Holbrook ML, Mogck EP, et al. (2004) The impact of modified Hatha yoga on chronic low back pain: a pilot study. Altern Ther Health Med 10(2): 56-59.

54. Williams KA, Petronis J, Smith D, Goodrich D, Wu J, et al. (2005) Effect of Iyengar yoga therapy for chronic low back pain. Pain 115(1-2): 107-117.
55. Harte JL, Eifert GH, Smit HR (1995) The effects of running and meditation on beta-endorphin, corticotropin-releasing Hormone and cortisol in plasma and on mood. Biol Psychol 40(3): 251-265.

56. Williams M, Solomonow M, Zhou BH (2000) Multifidus spasms elicited by prolonged lumbar flexion. Spine (Phila Pa 1976) 25(22): 2916-2924.

57. Cassidy EL, Atherton RJ, Robertson N (2010) Mindfulness, functioning and catastrophizing after multidisciplinary pain management for chronic low back pain. Pain 153(3): 644-650. 